\title{
Pitfalls in the management of panic disorder
}

\author{
EDWARD H. TOBE, DO
}

The need for treating the whole person is stressed in this paper. Three case reports show how complete assessment of the patient led to an understanding of the causes of the panic disorder so that a suitable treatment plan could be devised. Two of the patients were helped by administration of medication, although the presence of other psychologic problems suggests the need for additional treatment. The third patient, who had panic disorder with agoraphobia, was best aided by psychoanalysis. The importance of collaboration between family physician and psychiatrist is emphasized.

Panic disorder is an anxiety disorder characterized by recurrent panic attacks. Both the lay and medical literature is filled with articles about its diagnosis and treatment. The purpose of this article is to demonstrate that panic disorder may have different causes and therefore requires individualized treatment. To clarify this point, three cases will be reported.

The diagnostic criteria for panic disorder in DSMIII-R ${ }^{1}$ are as follows:

A. At least three panic attacks within a three-week period in circumstances other than during marked physical exertion or in a life-threatening situation. The attacks are not precipitated only by exposure to a circumscribed phobic stimulus.

B. Panic attacks are manifested by discrete periods of apprehension or fear, and at least four of the following symptoms appear during each attack: (1) dyspnea, (2) palpitations, (3) chest pain or discomfort, (4) choking or smothering sensations, (5) dizziness, vertigo, or unsteady feelings, (6) feelings of unreality, (7) paresthesias (tingling in hands or feet), (8) hot and cold flashes, (9) sweating, (10) faintness, (11) trembling or shaking, (12) fear of dying, going crazy, or doing something uncontrolled during an attack.

C. Not due to a physical disorder or other mental disorder such as Major Depression, Somatization Disorder, or Schizophrenia.

D. The disorder is not associated with Agoraphobia.

Although agoraphobia is a common complication of panic disorder, the DSM-III prefers to consider this complication an "Agoraphobia with Panic Attacks."

The constellation of symptoms quoted has been studied extensively. Considerable interest has been shown in the biochemical aspects of panic disorder to assess their role in anxiety and in the relationship to depressive disorders for diagnostic and pharmacologic treatment consideration. As an example, panic-disorder patients have been reported to show reduced prolactin and thyroid-stimulating hormone responses to thyrotropin-releasing hormone ${ }^{2}$ resembling responses in patients with a major depression. Some panic-disorder patients respond to lactate infusion by developing florid symptoms. ${ }^{3-5}$ Whether panic-disorder patients show increased frequency of abnormal results of the dexamethasone suppression test, as supposedly seen in depression, versus controls, is controversial. ${ }^{6-8}$

A variety of treatments, such as behavioral relaxation techniques, monoamine-oxidase inhibitors, tricyclic antidepressants, and alprazolam, have been advocated ${ }^{9,10}$ To make the best choice of therapy, however, the physician must evaluate the whole person. Unfortunately, some factors complicate this complete assessment. The literature offers studies of the treatment responses of large groups of patients with similar symptoms, ${ }^{11,12}$ but the similarity is misleading when the individual patient is considered. Some patients want to believe that panic disorder is isolated from their personal difficulties and therefore treatable without regard to these problems.

To clarify the significance of a careful, individual evaluation, I present the following examples. Each of the patients had a thorough work-up by the family physician with unremarkable physical findings. The family physicians referred these patients for psychiatric evaluation because of the severe, unremitting quality of their symptoms. The physicians assured them that the referral was not an indictment of insanity but, rather, part of a medical process to help them. The family physicians assured the patients of their ongoing involvement with their care. The support from the family physician was critical to the evaluation and initial phase of treatment, especially for the patient in case 3. 


\section{Case reports}

\section{Case 1}

A 35-year-old, married, high-school educated man was seen with severe anxiety of three months' duration, meeting all the diagnostic criteria for panic disorder. Immediately after his parents, who lived nearby, informed him of their decision to move to a distant state, he fell to the living room floor and developed severe unremitting anxiety. He became unable to work.

The patient believed that he had always enjoyed good physical and mental health prior to the onset of the severe anxiety. Yet, a psychiatric history revealed that he was hypomanic. With endless energy, he enjoyed working long hours. He was known at work as 'Mr. Hyper.' He required little sleep. Although he denied any family history of mental illness, the question of the family psychiatric history remains open, because of his tendency to deny problems.

I placed the patient on a regimen of imipramine, a commonly used tricyclic antidepressant. Within a few weeks, he was back at work, free of any panic symptoms, once again 'Mr. Hyper.' Three months later, he independently discontinued the imipramine, and his symptoms quickly reappeared. He consulted me again, and I suggested reinstituting the medications. He cooperated, and his symptoms quickly disappeared. I referred him to his family physician and have had no further follow-up. This man was seen because of a panic disorder, but he also had an affective disorder, hypomania.

\section{Case 2}

The patient was a high-school educated, 25-yearold mother of two children who was separated from her husband. When first seen, she met the diagnostic criteria for panic disorder. The severe anxiety started without clear cause. She had led a chaotic life with a theme of 'getting over' (that is, exploiting) others. She felt comfortable with lying, cheating, and fraud. She requested that I defraud her insurance company by billing excessive visits. Her husband had a criminal history. She had been abusing amphetamines and marijuana for several years. The patient denied any change in her pattern of drug abuse prior to the development of panic disorder.

I suggested that she terminate all illegal drugs. She claimed that she had already done so, one month prior to our first meeting, without improvement in her symptomatology. Because her family physician had already started alprazolam therapy at a low dosage, I continued the regimen but increased the dose. She improved immediately. Af- ter two weeks, I terminated the alprazolam therapy and her symptoms reappeared. The alprazolam regimen was begun again and her symptoms disappeared.

The patient saw no reason for counseling about her life. When I told her it was not surprising that symptoms developed in view of her chaotic life, she only laughed. The diagnosis of severe personality disorder (borderline or antisocial) needs to be considered, along with concerns about the role of drug abuse in creating her symptoms.

\section{Case 3}

A college-educated, married woman in her mid30 s was referred for a panic disorder meeting all the diagnostic criteria for panic disorder with agoraphobia. Several months before our first meeting, the patient had just re-enrolled in additional college work to change her career goals when she experienced a sudden onset of symptoms of a panic attack in the classroom. Within a few weeks after the onset of her attacks, fears of public places and of being alone developed. She rationalized that she avoided public places and being alone so that she would feel safe during any future panic attack. Although afraid, she forced herself to work, barely able to tolerate working 20 hours per week.

The patient's mother had suffered with severe and, at times, incapacitating anxiety and depression for many years. Also, her only sister had a history suggestive of depression.

This patient felt that her problems were a reflection of how her life had evolved, and she elected a treatment to correct this adverse evolution, rather than medication, biofeedback, and behavioral techniques. She entered a classical psychoanalysis. Psychoanalysis is a complex process, studying all areas of the patient's life; but, for this article, I shall present only the major theme pertaining to the agoraphobia and panic attacks.

Early in psychoanalysis, the patient recalled a forgotten incident causing the development of agoraphobia. As preliminary information, the patient and her mother had a mutually dependent relationship. The patient resented the mother's frequent, repetitive, pressing demands. The patient was unaware of her own contribution to this problematical relationship. If the patient did not give in to these demands, the mother felt outraged and accused the guilt-ridden patient of an unloving, uncaring attitude. On the day the agoraphobia began, the patient handled her mother's demands to accompany her to grocery shopping by lying and saying that the patient was not going to the store. At the store, the patient felt guilty for lying and had a fleeting picture of her mother 
without any food. The patient forgot her lie and her mental image of her mother's empty refrigerator, and instead acute fear of public places developed. When the analysis uncovered this forgotten memory, the agoraphobia subsided, but the panic attacks continued.

The agoraphobia was not as the patient had previously thought, a fear of the panic attacks occurring in public but, rather, part of her punishment for her imagined ill treatment of her mother. The analytic work focused on resolving the patient's competitive and dependent attitudes toward her mother. When the patient felt "better" than her mother and "independent of mother," a panic attack would develop. We clarified that the panic attack served as the signal for the emergence of conflicting concerns. The patient wanted independence and high achievement, but she imagined that this accomplishment somehow harmed her mother. The panic attack made the patient too sick to be independent and successful; instead, she became as sick and dependent as her mother.

With these clarifications, the panic disorder disappeared. The analysis eventually helped her to understand the origins of her previously unconscious view that her success equaled her mother's demise. Of course, the analysis also addressed other issues. It relieved not only the panic attacks but also severe inhibitions that the patient had never recognized but that had impaired her work and marriage.

The diagnosis was an acute onset of a neurosis.

\section{Discussion}

The purpose of these brief examples is to indicate that the diagnosis of panic disorder does not indicate the kind of treatment needed, nor does the diagnosis offer sufficient information about the patients. A complete understanding of the patient's life is necessary to determine the best way to intervene. The first patient needs to be monitored over an extended period for the possible development of a depression or manic episode. His hypomania may jeopardize his judgment and relationships and make him unaware of the seriousness of his circumstances. The second patient is on the road to doom, perhaps a doom she will never recognize. Her children are also at risk. Through her delinquency, her problems may have a negative impact on society. For the patient in case 3, medication or biofeedback or behavioral techniques would have been a grave disservice. She needed an opportunity to address her life's major problems. The psychoanalysis freed her not only from the panic attacks, but also from those inhibitions that had prevented her from reaching her full potential at work and in marriage.

I have attempted to stress the need for a complete psychiatric evaluation in patients with symptoms indicating a panic disorder. Using the panicdisorder diagnosis as a complete assessment will misdirect the physician's management of the patient. Only a very careful assessment of the whole person can lead to an understanding of the causative factors, and allow formulation of a treatment plan suitable to that individual's needs. Collaboration between psychiatrist and family physician is essential to offer the patient a cohesive medical position to support the treatment process.

1. American Psychiatric Association. Diagnostic and Statistical Manual of Mental Disorders, ed. 3 DSM-III. Washington, D.C., American Psychiatric Association, 1980.

2. Roy-Byrne PP, Uhde TW, Rubinow DR, et al: Reduced TSH and prolactin responses to TRH in patients with panic disorder. Am $J$ Psychiatry 1986;143:503-507.

3. Liebowitz MR, Gorman JM, Fyer A, et al: Possible mechanisms for lactate's induction of panic. Am J Psychiatry 1986;143:495-502.

4. Liebowitz MR, Fyer AJ, Gorman JM, et al: Lactate provocation of panic attacks: I. Clinical and behavioral findings. Arch Gen Psychiatry 1984;41:764-770.

5. Liebowitz MR, Gorman JM, Fyer AJ, et al: Lactate provocation of panic attacks: II. Biochemical and physiological findings. Arch Gen Psychiatry 1985;42:709-719.

6. Bueno J, Sabanes F, Gascon J, et al: Dexamethasone suppression test in patients with panic disorder and secondary depression, letter. Arch Gen Psychiatry 1984;41:723-724.

7. Lieberman JA, Brenner R, Lesser M, et al: Dexamethasone suppression tests in patients with panic disorder. Am J Psychiatry 1983;140:917919.

8. Sheehan DV, Claycomb JB, Surman OS, et al: Panic attacks and the dexamethasone suppression test. Am J Psychiatry 1983;140:1063-1064. 9. Ballenger JC: Current comments: The pharmacotherapy of agoraphobia with panic attacks. Curr Affective Illness/Lit Rev Comment 1985;4(March):5-8.

10. Klein DF: Currents interview: An update on panic disorder. Curr Affective Illness/Lit Rev Comment 1985;4(March):5-8.

11. Charney DS, Woods SW, Goodman WK, et al: Drug treatment of panic disorder: The comparative efficacy of imipramine, alprazolam, and trazodone. J Clin Psychiatr 1986;47:580-586.

12. Garakani H, Zitrin CM, Klein DF: Treatment of panic disorder with imipramine alone. Am J Psychiatry 1984;141:446-448.

From the Departments of Psychiatry, University of Medicine and Dentistry of New Jersey, School of Osteopathic Medicine, Cherry Hill, NJ, Robert Wood Johnson Medical School, Piscataway, NJ, and Hahnemann University, Philadelphia.

For reprints, address Dr Tobe, Suite D-19, 1930 E Route 70, Cherry Hill, NJ 08003. 


\section{Coming soon...}

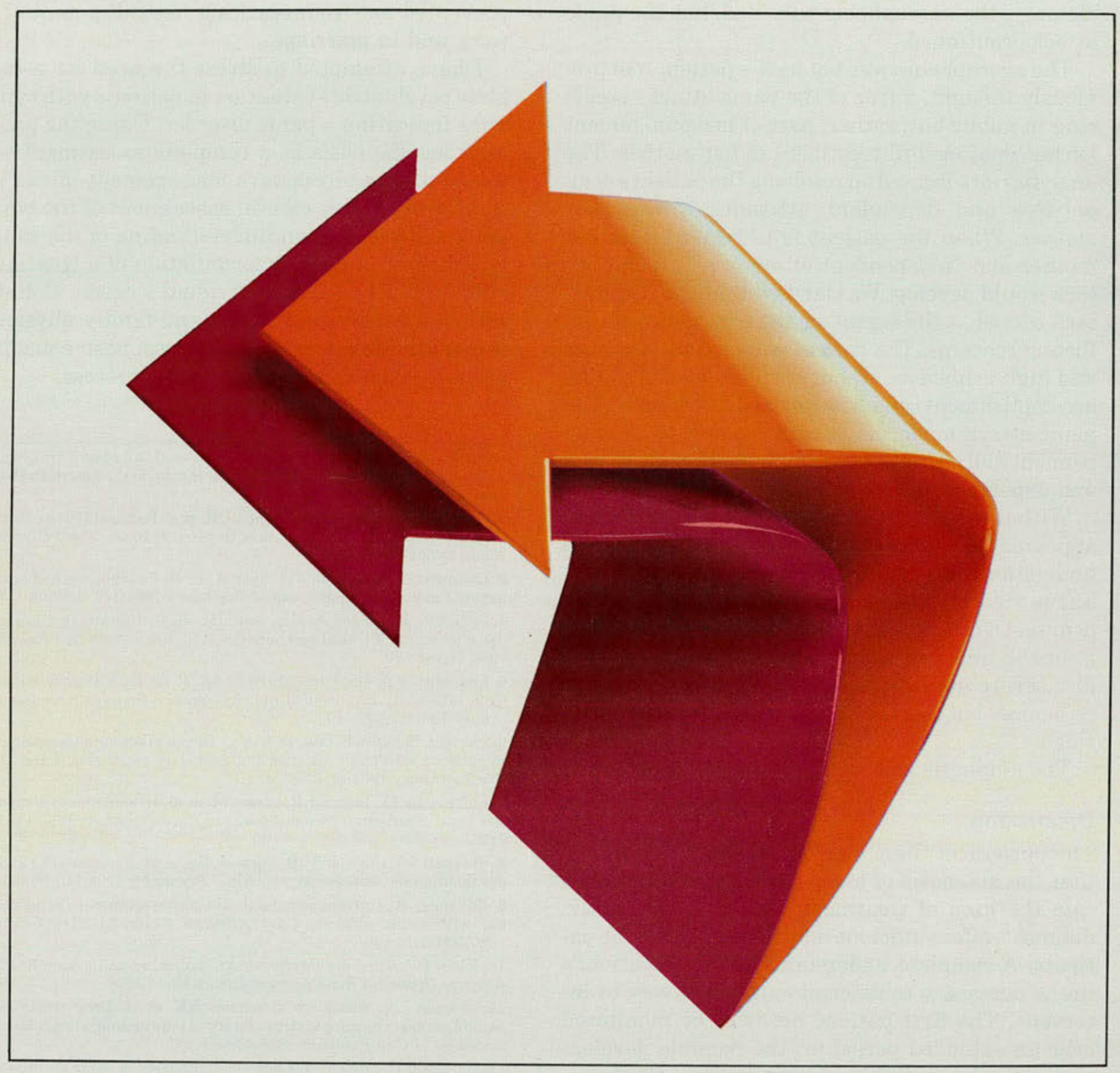

\section{An ideal new companion for}

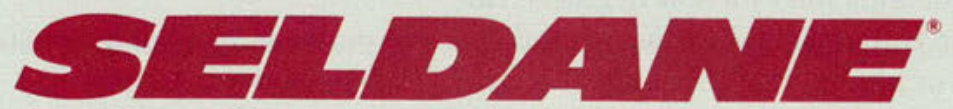

(terfenadine)

\section{Merrell Dow}

